\title{
Magnetic Pre-Loading for a Tonpilz-Type Acoustic Projector
}

\author{
Scott D. Moss ${ }^{a}$, Ethan J. G. Ellul ${ }^{b}$, Mason Paxevanos ${ }^{c}$, George Jung ${ }^{d}$, \\ David Munk ${ }^{\mathrm{e}}$, and Joel Smithard ${ }^{\mathrm{f}}$
}
Defence Science and Technology Group, Aerospace Division, 506 Lorimer Street, Fishermans Bend, Victoria, Australia, 3207
ascott.moss@dst.defence.gov.au, bethan.ellul@dst.defence.gov.au, cmason.pax@gmail.com, dgeorge.jung@dst.defence.gov.au, edavid.munk@dst.defence.gov.au, fjoel.smithard@dst.defence.gov.au
*Corresponding author. Tel.: +61-3-9626-7958; fax: +61-3-9626-7089.

(C) 2020 Commonwealth of Australia

\begin{abstract}
Keywords: Magnetic Force, Tonpilz, Acoustic Projector, Relaxor Ferroelectric Single Crystal
\end{abstract}

\begin{abstract}
This paper describes a new magnet-based method for applying a compressive pre-load to the piezoceramic elements of a Tonpilz-type acoustic projector, with the advantage of lower damping due to mechanical friction and a greater range of unhampered resonant motion since no plate spring is required. The Tonpilz-type acoustic projector can be applied to structural health monitoring studies involving air coupled ultrasound. Acoustic model predictions and the measured behaviour of a relaxor ferroelectric single crystal (RFSC) based prototype device, operating in air, are presented and show good correlation. With a $5 \mathrm{~V}$ drive, at $9420 \mathrm{~Hz}$ resonance, the prototype device generates a sound pressure level of $113 \mathrm{~dB}$ measured at an axial distance of $5 \mathrm{~mm}$. The maximum peak tip displacement of the device's head mass is predicted to be $0.7 \mu \mathrm{m}$ at resonance. This is well within the $2 \mu \mathrm{m}$ displacement produced by the $90 \mathrm{~N}$ magnetic pre-load, thus protecting the RFSC ceramic element from damaging tensile stress.
\end{abstract}

\section{Introduction}

Tonpilz acoustic projector designs typically use an axial bolt/nut, known as a tie-rod, to provide a static compressive pre-load to their constituent piezoceramic drive elements [1-3]. This compression prevents the elements from being driven into tension where they will likely fail. The resonant behaviour of Tonpilz designs is accommodated via a plate spring positioned mechanically in series with the piezoelectric drive elements [1]. The greater the pre-load, the greater the potential amplitude of operation. Tonpilz projectors are often associated with undersea operation [4,5], however they can also operate in air as an acoustic source for structural inspection techniques [6-8]. Recently, relaxor ferroelectric single crystals (RFSC) have been explored for use in electroacoustic applications including Tonpilz projectors, with their giant piezoelectric properties and high coupling coefficients proving beneficial [9-11]. The magnetic pre-loading approach described in this paper, and reported in reference [12], offers an alternate method for mechanically compressing the piezoceramic elements in an acoustic projector, permitting a simple, compact design with less frictional loss. The principles of operation will be discussed next, followed by a discussion of a multiphysics model developed for the prototype device. 
The principle design features for the magnetic pre-loading approach are shown in Fig. 1. The magnetic support structure depicted schematically in Fig. 1a is a series of ring magnets around a rectangular piezoelectric plate-element. The head magnet is attracted to the magnetic support structure, applying a compression to both the piezoceramic (RFSC hereafter) element and the spacer. The tail magnet completes the magnetic circuit. An example spacer is shown in Fig. 1b, with vertical ligaments that are designed to have a mechanical stiffness approximately ten times less than the crystal transducer. The ligament arrangement also protects the RFSC element from bending stress if the device is mounted horizontally. The centre of the spacer contains a square hole which aids crystal positioning during device manufacture. Fig. 1c shows a photograph of a prototype device, the tail and head magnets (labelled '2' and ' 3 ' respectively) having $20 \mathrm{~mm}$ diameter, the hidden RFSC element (labelled ' 1 '), and the thin disks of machinable glass $\left(\mathrm{MACOR}^{\mathrm{TM}}[13]\right.$, labelled ' 7 ') that protect the element from damage during mechanical loading.

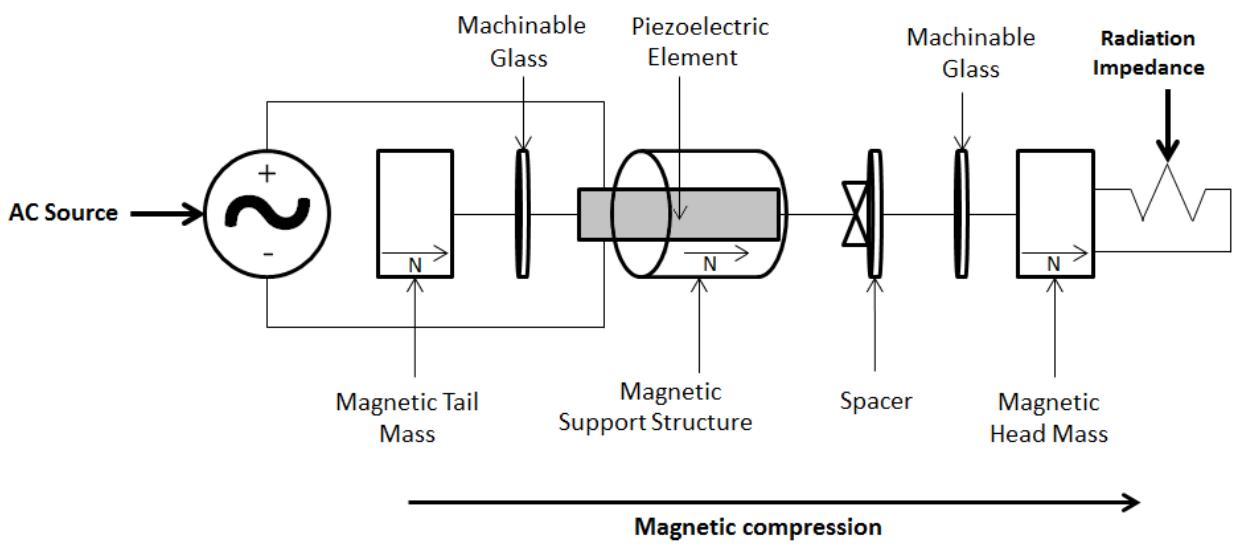

(a)

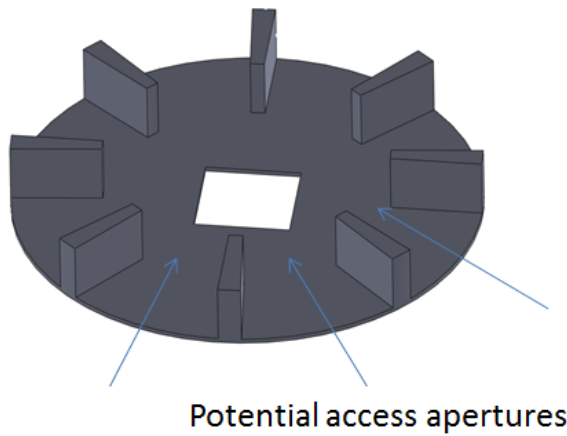

(b)

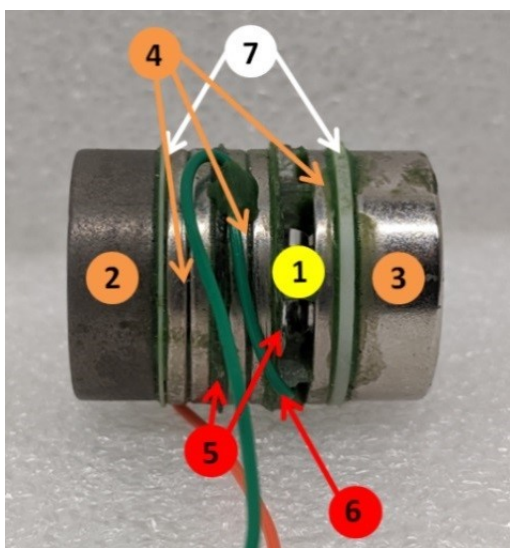

(c)

Figure 1. (a) Schematic of the magnetically pre-loaded Tonpilz-type acoustic projector. (b)

Schematic of the polycarbonate spacer. (c) Photograph of a prototype device showing: 1) Relaxor ferroelectric single crystal located inside the device, i.e. not visible, 2) SmCo base mass, 3) $\mathrm{NdFeB}$ head mass, 4) high temperature $\mathrm{NdFeB}$ rings, 5) polycarbonate spacers, 6) aperture in polycarbonate support allowing wire access, 7) machinable glass disks. 
Table 1. Physical properties of a free RFSC element.

\begin{tabular}{|l|c|}
\hline \multicolumn{1}{|c|}{ Physical Property } & Value for (011) Mn-PMN-PZ-PT \\
\hline Relative Permittivity, $\Sigma_{33}{ }^{\top}$ & 2500 \\
\hline Phase-Transition / Curie & $145 / 200$ \\
Temperatures, $T_{R-T} / T_{C}\left({ }^{\circ} \mathrm{C}\right)$ & \\
\hline Coercive Field, $\mathrm{E}_{\mathrm{C}}(\mathrm{kV} / \mathrm{cm})$ & 6 \\
\hline Piezo Constant, $\mathrm{d}_{32}(\mathrm{pC} / \mathrm{N})$ & -900 \\
\hline Coupling Factor, $\mathrm{k}_{32}$ & 0.86 \\
\hline Compliance, $\mathrm{s}_{22}{ }^{\mathrm{E}}\left(10^{-12} \mathrm{~m}^{2} / \mathrm{N}\right)$ & 69 \\
\hline Mechanical Quality, $\mathrm{Q}_{\mathrm{m}}$ & 1000 \\
\hline
\end{tabular}

\section{Modelling}

This section will discuss the multiphysics model developed to predict the behaviour of the acoustic projector shown in Fig. 1. The frequency-domain model developed for the prototype device couples (i) solid-mechanics, (ii) piezoelectrics, and (iii) pressure-acoustics in the air domain, and follows the approach described in reference [14]. Material properties for the RFSC element were taken from reference [15], with the more important material properties reproduced in Table 1. The model mesh used is shown in Fig. 2a, and has 75k elements. The mesh density of the hemispherical air domain was determined via a rule that there should be at least 6 nodes per wavelength for the highest modelled frequency, $\mathrm{f}_{\mathrm{MAX}}=12 \mathrm{kHz}$. The radius of the air domain was set to $r_{A I R}=\left\{2\left(c_{A I R} / f_{M A X}\right)\right\}$ where $c_{A I R}=330 \mathrm{~m} / \mathrm{s}$. Figure $2 b$ shows a close-up of the modelled prototype. Only the dynamic parts of the device were included in the model: the head magnet shown in pink, the RFSC element $12 \times 4 \times 4 \mathrm{~mm}^{3}$, and four $1 \times 1 \times 1 \mathrm{~mm}^{3}$ polymer cubes approximating the effect of the eight vertical polycarbonate ligaments shown in Fig. 1b. The modelled peak drive voltage was assumed to be $5 \mathrm{~V}$. Total mechanical damping for the prototype device was approximated by applying an isotropic structural loss factor (inverse of quality factor) to the RFSC element. The yellow coloured boundaries shown in Fig. $2 \mathrm{~b}$ were set as fixed constraints. The modelled frequency range was $8-12 \mathrm{kHz}$, and using $0.025 \mathrm{kHz}$ steps with $147 \mathrm{k}$ degrees-of-freedom the model took approximately 16 minutes to solve on a modern desktop PC.

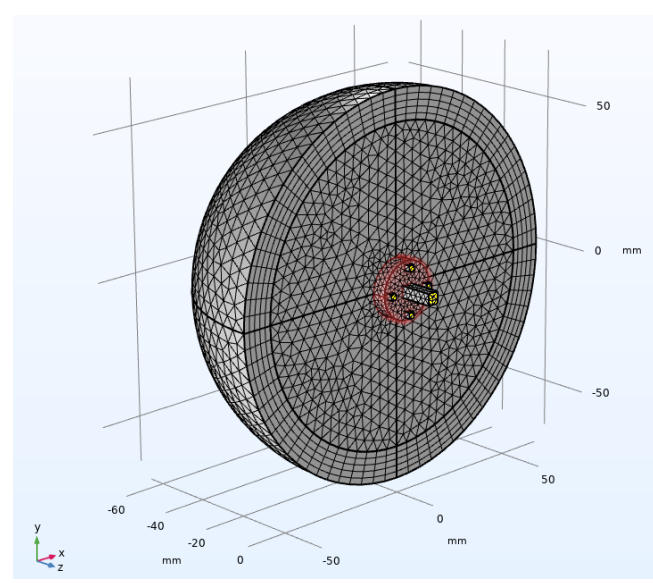

(a)

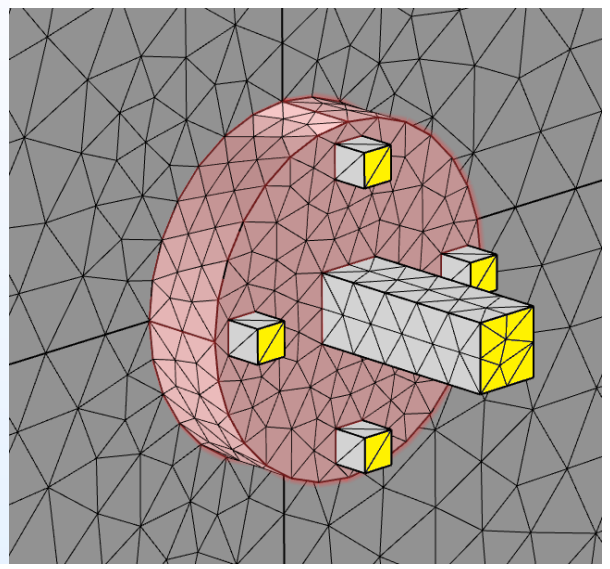

(b)

Figure 2. (a) Mesh used for multi-physics modelling of the acoustic projector, and (b) close-up showing the modelled prototype. 


\section{Experimental}

This section will present a brief overview of the device construction, and discuss the experimental arrangement used to characterise the acoustic behaviour of the prototype device.

As mentioned earlier, the prototype device shown in Fig. 1c uses an RFSC element being (011) poled Mn-PMN-PZ-PT having dimensions $12 \times 4 \times 4 \mathrm{~mm}^{3}$. An impedance sweep for a free RFSC element is provided in Fig. 3 and shows an impedance of $756 \mathrm{k} \Omega$ at $1000 \mathrm{~Hz}$, equivalent to a free capacitance of $214 \mathrm{pF}$. The prototype device was assembled using a structural adhesive (Click Bond CB359) with the RFSC element, magnets, and machinable glass disks bonded into place. Wires were connected to the RFSC element using silver epoxy (Chemtronics CW2400). After assembly, one week was allowed for the adhesives to cure at room temperature, after which the measured capacitance reduced to $\sim 152 \mathrm{pF}$. The magnetic arrangement for the prototype device uses a samarium cobalt ( $\mathrm{SmCo}$ ) base mass, a neodymium boron iron $(\mathrm{NdFeB})$ head mass, and high temperature $\mathrm{NdFeB}$ rings. The compressive force produced by the magnetic arrangement is estimated at $90 \mathrm{~N}$, producing an estimated $2 \mu \mathrm{m}$ of compressive displacement on the RFSC element.

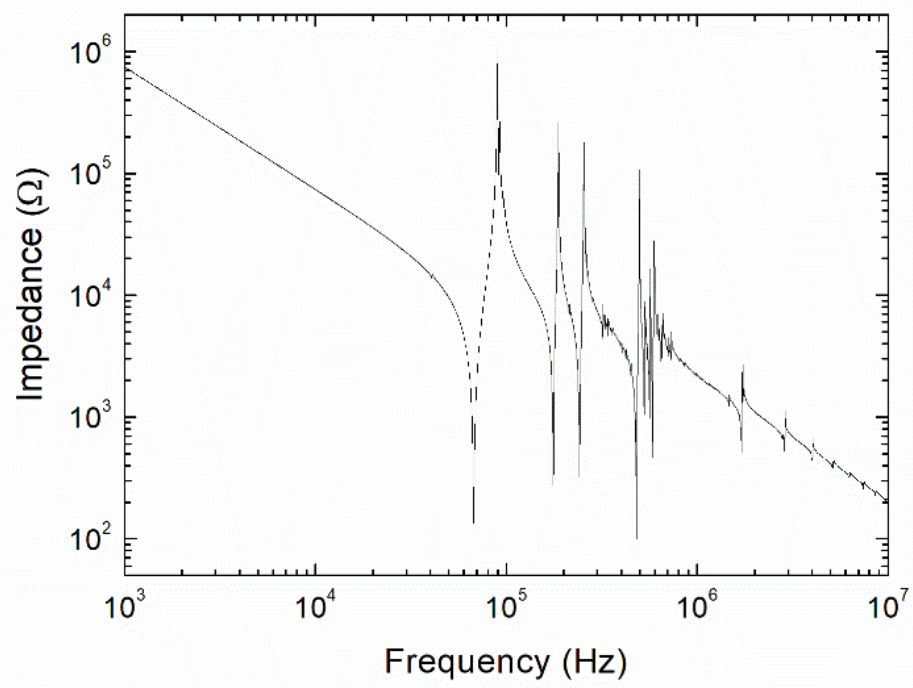

Figure 3. Measured impedance of a $12 \times 4 \times 4 \mathrm{~mm}^{3} \mathrm{Mn}-P M N-P Z-P T$ element.

A miniature high-performance microphone (Knowles Zero-Height SiSonic, SPU0410LR5HQB) was used to measure acoustic pressure in air. The microphone has a reasonably flat sensitivity curve $+/-2 \mathrm{~dB}$ between $0.1-10 \mathrm{kHz}$, and can also be used to measure ultrasonic frequencies up to $80 \mathrm{kHz}$. Figure 4a shows a schematic of the 10x gain preamplifier circuit built to power and interrogate the microphone. The circuit was designed to run off a $9 \mathrm{~V}$ battery and uses a voltage splitter to produce a symmetrical +/- $4.5 \mathrm{~V}$ supply for the amplifier. Power to the microphone is supplied via two forward biased Zener diodes, limiting the voltage to less than 3.6 $\mathrm{V}$. The direct current (DC) blocking capacitor was chosen so that its effective impedance is insignificant at the frequencies of interest. A photograph of the sound measurement arrangement is shown in Fig. 4b, with a prototype device mounted on a large steel backing plate, and the gap between the prototype device and the microphone measured with an error of $+/-0.25 \mathrm{~mm}$. The drive signal for the prototype device was continuous wave with $5 \mathrm{~V}$ peak. The reference level for acoustic sound pressure measurement in air is $20 \mu \mathrm{Pa}$; the sound pressure level (SPL) of $1 \mathrm{~Pa}$ can hence be found via the calculation $20 * \log (1[\mathrm{~Pa}] / 0.00002[\mathrm{~Pa}])=94 \mathrm{~dB}$ SPL. The voltage 
reference level for $\mathrm{dBV}$ is $1 \mathrm{~V}$, dividing by 20 and taking the inverse log we find $-38 \mathrm{dBV}=$ $0.0126 \mathrm{~V}$. Therefore, at $1 \mathrm{~Pa}$, the sensitivity is $0.0126 \mathrm{~V} / \mathrm{Pa}$.

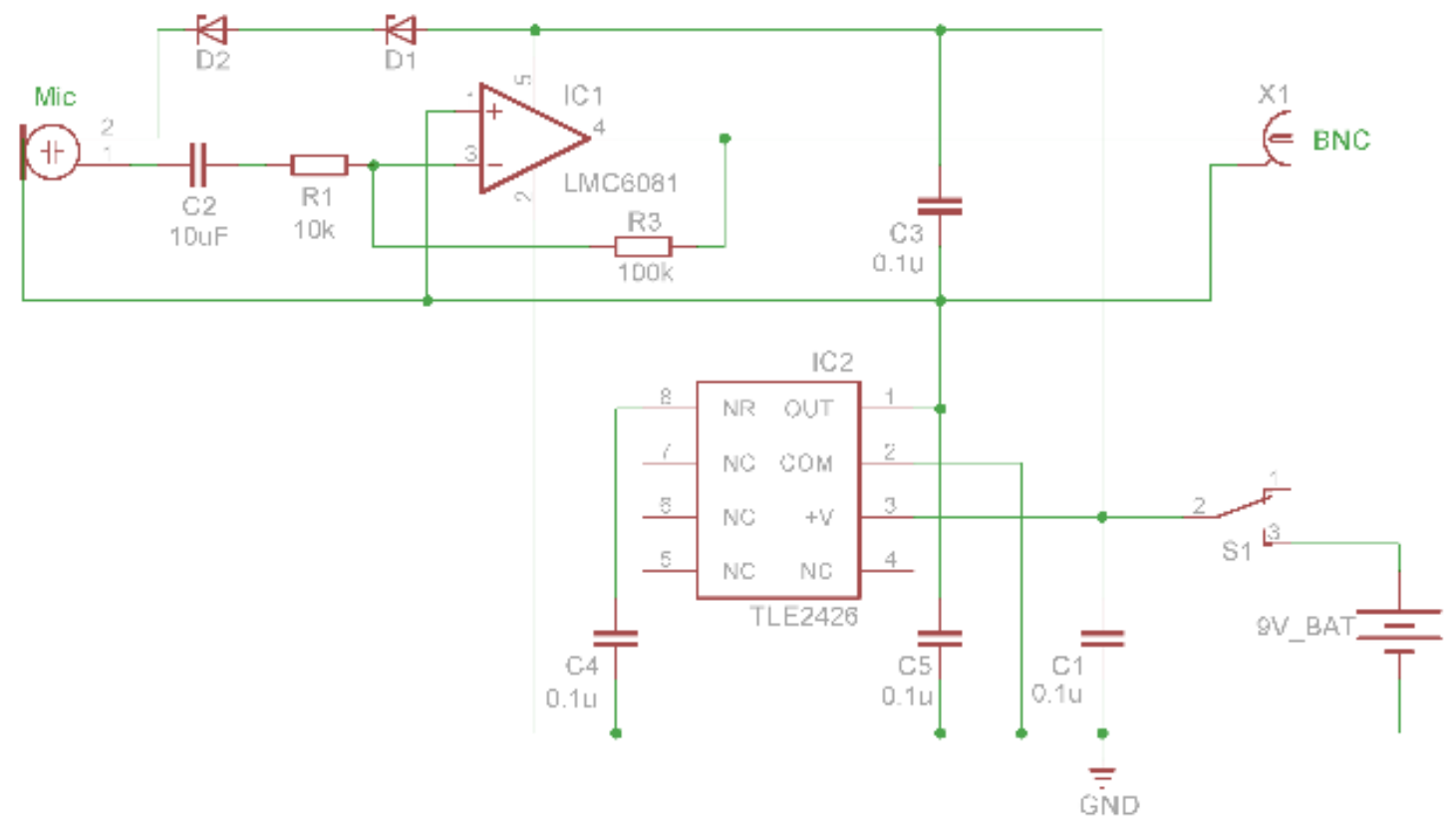

(a)

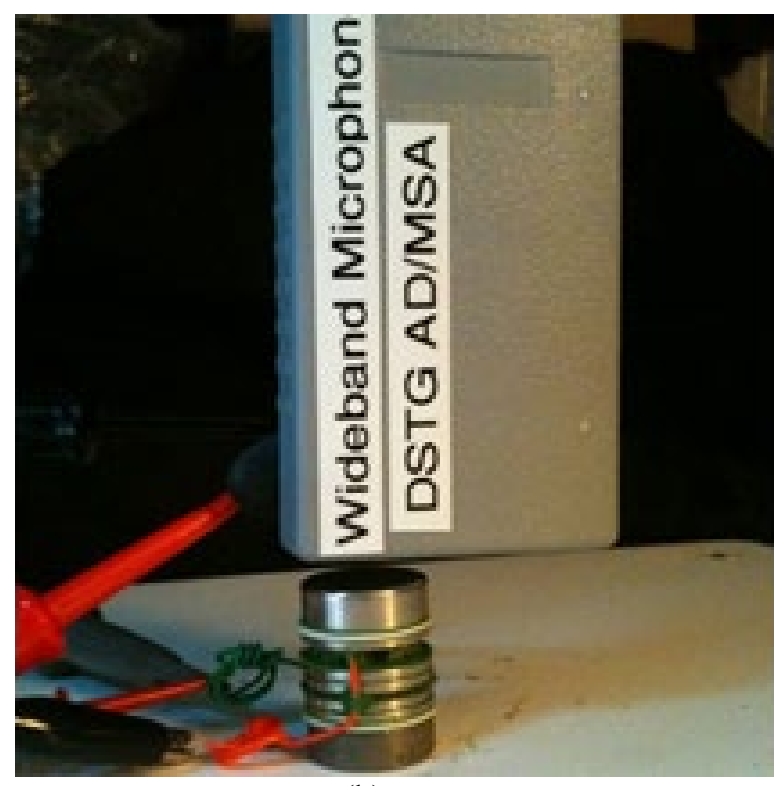

(b)

Figure 4. (a) Microphone circuit, and (b) sound measurement arrangement. 


\section{Results and discussion}

The measured acoustic response of the prototype device is discussed including the measured quality factor, which is important for accurate modelling. A comparison with the model predicted acoustic pressure and sound pressure levels is undertaken, and the predicted acoustic power and head mass displacements are discussed.

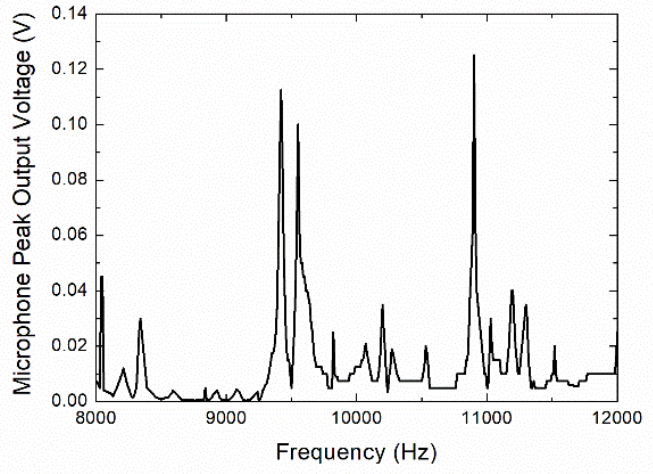

(a)

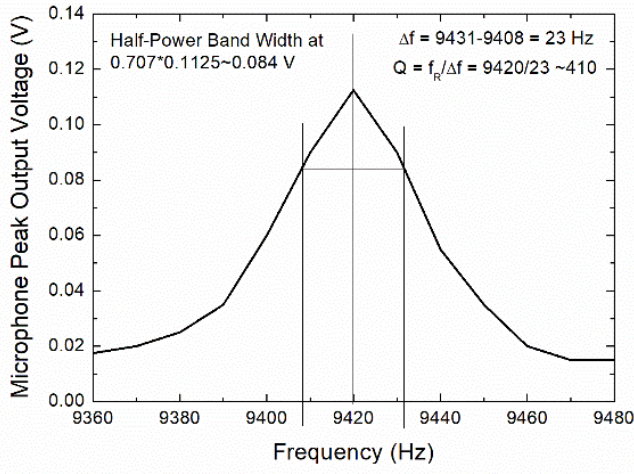

(b)

Figure 5. (a) Measured voltage equivalent for sound pressure level, and (b) half-powerbandwidth for $9420 \mathrm{~Hz}$ resonance.

Figure 5(a) shows the measured peak output voltage, across the range $8-12 \mathrm{kHz}$, with a distance of $5 \mathrm{~mm}$ between the top surface of the prototype device and the microphone. The measured resonance found at $9420 \mathrm{~Hz}$ is assumed to be the peak of interest. Using a $5 \mathrm{~V}$ peak drive signal at a frequency of $9420 \mathrm{~Hz}$, the measured output from the microphone circuit (Fig. 4a) was $2.25 \mathrm{~V}$ peak-peak. Dividing this output by the 10x gain factor of the preamplifier circuit and also by $2 \mathrm{x}$ (and thus converting to peak values) yields the $0.1125 \mathrm{~V}$ maximum peak voltages shown in Fig. 5a and 5b. The $0.1125 \mathrm{~V}$ peak microphone output is equivalent to 0.1125 $[\mathrm{V}] / 0.0126[\mathrm{~V} / \mathrm{Pa}] \sim 8.93 \mathrm{~Pa}$. Based on this pressure, the measured sound pressure level is $20 * \log (8.93[\mathrm{~Pa}] / 0.00002[\mathrm{~Pa}])=\sim 113 \mathrm{~dB}$ SPL. Figure $5 \mathrm{~b}$ shows a close-up of the peak at 9420 $\mathrm{Hz}$, from which the measured quality factor $\mathrm{Q}=410$ was calculated using the half-power bandwidth at the voltage multiple of 0.707. As expected, the measured quality factor is smaller than that of the RFSC crystal dielectric loss (i.e. Table 1, material $\mathrm{Q}_{\mathrm{M}}=1000$ ), with additional damping due to adhesive bond-lines, parasitic reactive elements, and friction. Inverting the measured quality factor yields the isotropic structural loss factor value of 0.0024 , which was implemented in the multiphysics model, yielding the model predictions shown in Fig. 6 a-d for a drive of $5 \mathrm{~V}$ peak at the model predicted resonance frequency $8750 \mathrm{~Hz}$.

The modelled acoustic pressure shown in Fig. $6 \mathrm{a}$ and $6 \mathrm{~b}$ indicates a $38 \mathrm{~mm}$ wavelength, which is expected. A second-order exponential fit was made to envelope the modelled acoustic pressure, approximated by the red curves in Fig. 6b. The exponential fit details for the upper envelope is inset into Fig. 6b; this envelope equation is used to calculate the maximum peak acoustic pressure of $\sim 9.03 \mathrm{~Pa}$ at the location $\mathrm{z}=-5 \mathrm{~mm}$, i.e. $5 \mathrm{~mm}$ away from the end of the magnetic head mass. The $9.03 \mathrm{~Pa}$ acoustic pressure prediction is a good match to the $8.93 \mathrm{~Pa}$ measured at the same location (as discussed in the paragraph above). The model predicted SPL distribution is shown in Fig. 6c, with a maximum predicted $116 \mathrm{~dB}$ SPL right at the end surface of the head mass. Both the predicted and measured sound pressure levels are $113 \mathrm{~dB}$ SPL at a distance $5 \mathrm{~mm}$ from the head mass. With a $5 \mathrm{~V}$ drive at the resonant frequency $8750 \mathrm{~Hz}$, the model predicts a peak displacement of $0.7 \mu \mathrm{m}$ for the head mass, and a total radiated acoustic 
power of $\sim 1.3 \mathrm{~mW}$ (Fig. $6 \mathrm{~d}$ ), both of which have yet to be experimentally validated. The $0.7 \mu \mathrm{m}$ peak displacement produced at resonance is well within the $2 \mu \mathrm{m}$ compressive displacement produced by the magnetic arrangement, so theoretically the RFSC element should be protected from damage due to tensile loading. It is expected that the magnetic pre-load arrangement will continue to protect the RFSC element from tensile stress as higher acoustic powers and frequencies, including ultrasonic and beyond, are explored in future work.

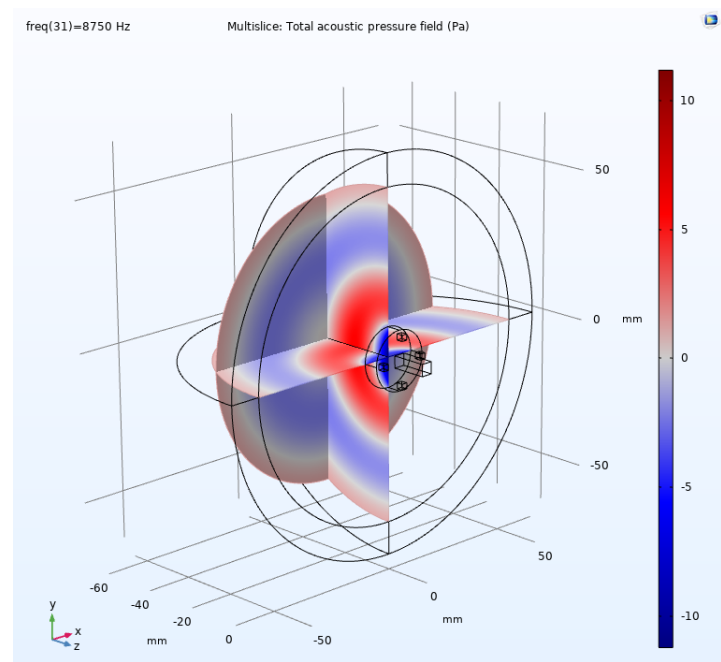

(a)

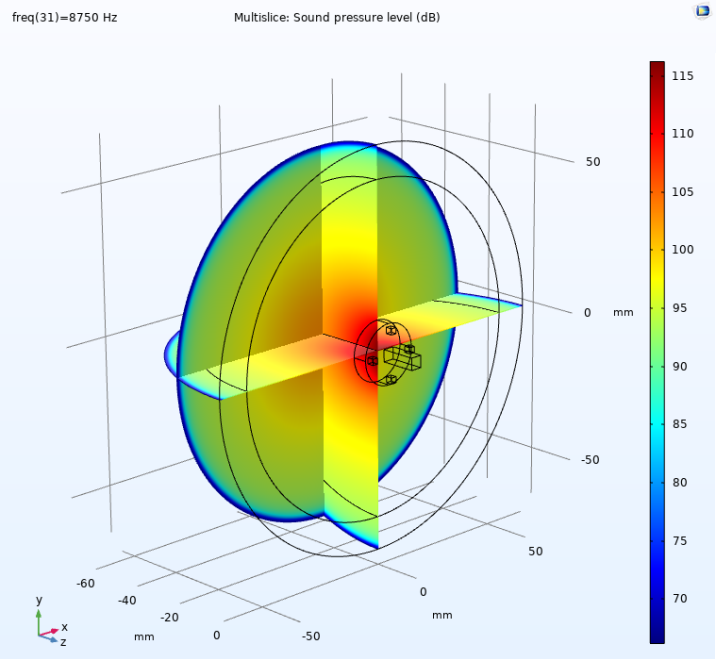

(c)

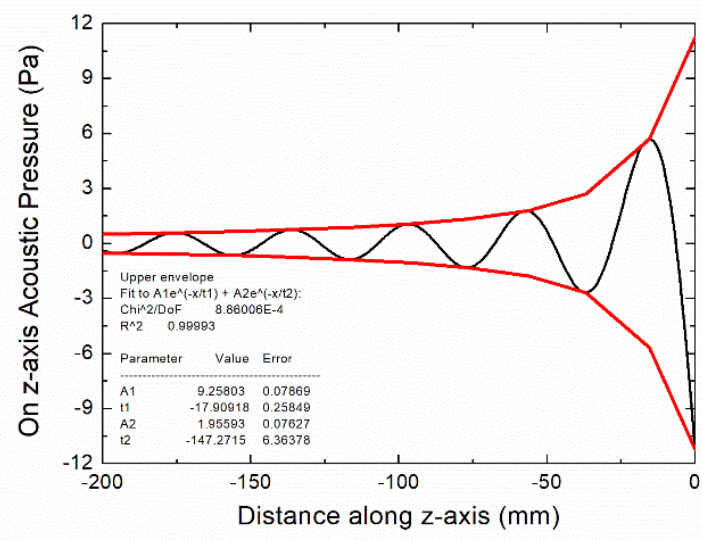

(b)

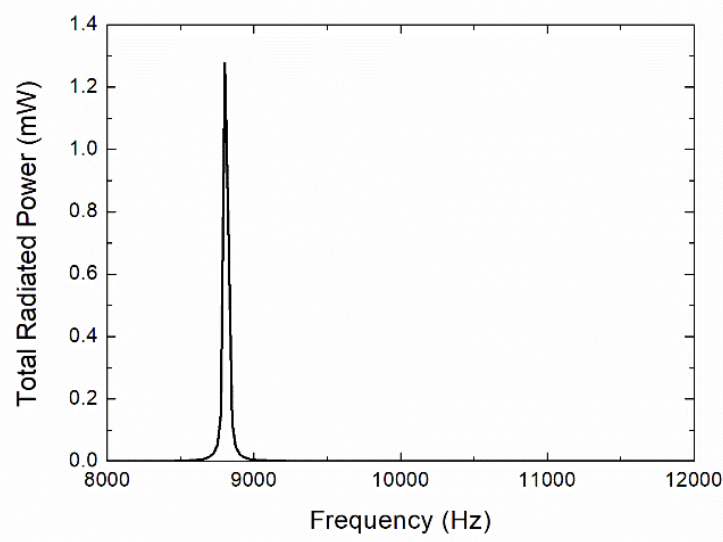

(d)

Figure 6. Model predictions of (a) acoustic pressure, (b) pressure distribution in axial (z-axis) direction with red envelope functions, (c) sound pressure level, and (d) total radiated power.

\section{Conclusion}

This paper reports on a new magnet-based method for applying a compressive pre-load to the piezoceramic drive element of a Tonpilz-type device. This method of compression does not require a plate spring, which means there is less mechanical friction and therefore lower damping. To demonstrate the magnetic pre-loading approach, a relaxor ferroelectric single crystal based Tonpilz-type device has been developed. The device will be used as an acoustic source for structural health monitoring studies, such as air coupled ultrasound. Acoustic model 
predictions and the measured behaviour of a prototype device, operating in air, are presented and show good correlation. With a $5 \mathrm{~V}, 9420 \mathrm{~Hz}$ drive, the prototype device generates acoustic pressures of $9 \mathrm{~dB}$ at a $5 \mathrm{~mm}$ axial distance from the device, equivalent to a sound pressure level of $113 \mathrm{~dB}$. Model predictions of the acoustic pressures and sound pressure levels correlate well with measured values. The tip displacement of the magnetic head mass at resonance is predicted to be $0.7 \mu \mathrm{m}$ peak, well within the $2 \mu \mathrm{m}$ displacement produced by the $90 \mathrm{~N}$ of compressive force generated by the magnetic arrangement, thus protecting the ceramic transducer element from damaging tensile loading.

\section{References}

[1] P. Kurt, M. Şansal, İ. Tatar, C. Duran, S. Orhan, Vibro-acoustic design, manufacturing and characterization of a tonpilz-type transducer, Applied Acoustics. 150 (2019) 27-35. https://doi.org/10.1016/j.apacoust.2019.02.003

[2] T. Inoue, T. Sasaki, K. Sugiuchi, A. Hattori, A Design Method for Tonpilz Piezoelectric Underwater Transducer, Jpn. J. Appl. Phys. 29 (1990) 56-58.

https://doi.org/10.7567/JJAPS.29S1.56

[3] S. C. Thompson, R. J. Meyer, D. C. Markley, Performance of tonpilz transducers with segmented piezoelectric stacks using materials with high electromechanical coupling coefficient, The Journal of the Acoustical Society of America. 135 (2014) 155. https://doi.org/10.1121/1.4837217

[4] J.-N. Decarpigny, B. Hamonic, O.B. Wilson, The design of low frequency underwater acoustic projectors: present status and future trends, IEEE Journal of Oceanic Engineering. 16 (1991) 107 - 122. https://doi.org/10.1109/48.64890

[5] A. Amin, E. McLaughlin, H. Robinson, L. Ewart, Mechanical and Thermal Transitions in Morphotropic PZN-PT and PMN-PT Single Crystals and Their Implications for Sound Projectors, IEEE Trans. Ultrasonics, Ferroelectrics, and Freq. Control. 54 (2007) 1090 - 1095. https://doi.org/10.1109/TUFFC.2007.362

[6] K. A. Tsoi, N. Rajic, Non-destructive Evaluation of Aircraft Structural Components and Composite Materials at DSTO Using Sonic Thermography, DSTO-TN-0986, 2011.

[7] W. Hillger, D. Ilse, L. Bühling, H. Ing. Büro, Lamb-Waves for Air-coupled Ultrasonic Testing with one-sided Access, 8th European Workshop on Structural Health Monitoring (EWSHM 2016), 2016.

[8] J. Buckley, Air Coupled Ultrasound - A Millennial Review, 15 ${ }^{\text {th }}$ World Conference on NonDestructive Testing, 2000.

[9] K. Zhang, Y. Chen, K. Peng, The Study of 32-Mode Single Crystal Longitudinal Transducer, IEEE/OES China Ocean Acoustics Symposium, 2016. https://doi.org/10.1109/COA.2016.7535709

[10] S. Zhang, F. Li, X. Jiang, J. Kim, J. Luo, X. Geng, Advantages and challenges of relaxor$\mathrm{PbTiO} 3$ ferroelectric crystals for electroacoustic transducers - A review, Progress in Materials Science, Volume 68, March 2015, Pages 1-66. https://doi.org/10.1016/j.pmatsci.2014.10.002 
[11] C. Okawara, H. Robinson, J. Stace, A. Amin, "Electromechanical properties of highcoupling (1- $\xi) \mathrm{Pb}(\mathrm{Zn} 1 / 3 \mathrm{Nb} 2 / 3) \mathrm{O} 3-(\xi) \mathrm{PbTiO} 3$ single crystals for sound projectors", IEEE Transactions on Ultrasonics, Ferroelectrics, and Frequency Control. 57 (2010) 1497 - 1504. https://doi.org/10.1109/TUFFC.2010.1580

[12] Australian Provisional Patent 20200900680, Vibration Energy Transduction Devices and systems, $5^{\text {th }}$ March 2020.

[13] https://www.corning.com/au/en/products/advanced-optics/product-materials/specialty-glassand-glass-ceramics/glass-ceramics/macor.html

[14] https://www.comsol.com/model/piezoelectric-tonpilz-transducer-11478

[15] B. S. Vien, S. D. Moss, W. K. Chiu, J. Thornton, C. Rosalie, N. Rajic, T. F. Doughney, and H. J. Kissick, Measured Lamb wave radiation patterns from $\langle 011\rangle$ Mn-PMN-PZT relaxor ferroelectric disks on an isotropic plate, Appl. Phys. Lett. 113 (2018) 122902.

https://doi.org/10.1063/1.5044671 